REVISTA AMBIENTE CONTÁBIL

Universidade Federal do Rio Grande do Norte

ISSN 2176-9036

Vol. 10. n. 1, jan./jun. 2018

Sítios: http://www.periodicos.ufrn.br/ambiente http://ccsa.ufrn.br/ojs/index.php?journal=contabil http://www.atena.org.br/revista/ojs-2.2.3-06/index.php/Ambiente

Artigo recebido em: 29.11.2016. Revisado por pares em: 10.02.2017. Nova submissão em: 28.07.2017. Nova avaliação pelos pares em 06.08.2017. Reformulado em: 23.08.2017. Avaliado pelo sistema double blind review.

\title{
GERENCIAMENTO DE IMPRESSÃO GRÁFICA NO PROCESSO DECISÓRIO
}

\section{IMPRESSION MANAGEMENT IN THE DECISION-MAKING PROCESS}

\section{ADMINISTRACIÓN DE IMPRESIÓN GRÁFICA NO PROCESSO DECISÓRIO}

\section{Autores}

\section{Mariana Pereira Bonfim}

Doutoranda em Ciências Contábeis pela Universidade de Brasília (UnB). Professora Assistente do Departamento de Ciências Contábeis da Universidade Federal Fluminense UFF (Volta Redonda). Endereço: Campus Darcy Ribeiro - Prédio da FACE, Sala C1-72/13 Asa Norte - Brasília - DF - Brasil. CEP: 70.910-900. Telefone: (61) 3107-0812. Identificadores (ID): Lattes: http://lattes.cnpq.br/6281056363283128 E-mail: marianapbonfim@gmail.com

Ilka Gislayne de Melo Souza Doutoranda em Ciências Contábeis pela Universidade de Brasília (UnB). Funcionária pública da Prefeitura Municipal de Belo Jardim. Professora da Faculdade do Vale do Ipojuca (FAVIP DEVRY) e Faculdade de Ciências e Letras de Caruaru (FAFICA). Endereço: Campus Darcy Ribeiro - Prédio da FACE, Sala C1-72/13 - Asa Norte - Brasília - DF - Brasil. CEP: 70.910900. Telefone: (61) 3107-0812. Identificadores (ID): Lattes: http://lattes.cnpq.br/4674681682847076

E-mail: ilkacarter@hotmail.com

César Augusto Tibúrcio Silva Doutor em Controladoria e Contabilidade pela USP. Professor da Universidade de Brasília. Endereço: Campus Darcy Ribeiro - Prédio da FACE, Sala A1-112/4 - Asa Norte - Brasília DF - Brasil. CEP: 70.910-900. Telefone: (61) 31073300. Identificadores (ID): Research Gate: https://www.researchgate.net/profile/Cesar_Augusto_Tiburcio_Silva Lattes: http://lattes.cnpq.br/5727021339190342 E-mail: cesartiburcio@unb.br

Alex de Oliveira Serafim Bacharel em Ciências Contábeis pela DeVry | UNIFAVIP - Centro Universitário do Vale do Ipojuca. Endereço: Rua Adiar da Silva Casé, S/N - Indianópolis - Caruaru - Pernambuco - 
Mariana Pereira Bonfim, Ilka Gislayne de Melo Souza, César Augusto Tibúrcio Silva e Alex de Oliveira Serafim

ORCID: http://orcid.org/0000-0002-5389-3688

E-mail: alexolliveira@msn.com

\begin{abstract}
RESUMO
Este trabalho teve como objetivo verificar se a forma como os gráficos com informações contábeis é apresentada pode (ou não) influenciar o processo decisório dos estudantes de contabilidade. Foram obtidas 108 respostas por meio da aplicação de um questionário com gráficos de empresas hipotéticas nos quais foram utilizados gerenciamento de impressão na forma de seletividade, melhora da apresentação e distorção de medidas. Os resultados do estudo evidenciam que o gerenciamento de impressão gráfica influencia na tomada de decisão, uma vez que as alternativas que apresentavam estas situações foram escolhidas em $40 \%$ dos casos. De uma maneira geral, as características do indivíduo não foram relevantes para o resultado, sendo talvez um indicativo do gerenciamento abranger a qualquer tipo de pessoa.
\end{abstract}

Palavras-chave: Gerenciamento de Impressão. Gráficos. Usuários.

\begin{abstract}
This paper aimed to verify if the way in which the graphs with accounting information are presented may (or may not) influence the accounting students' decision making process. A total of 108 responses were obtained through the application of a questionnaire with charts of hypothetical companies in which print management was used in the form of selectivity, improved presentation and measurement distortion. The results of the study show that graphic print management influences decision making, since the alternatives that presented these situations were chosen in $40 \%$ of the cases. In general, the characteristics of the individual were not relevant to the result, and perhaps an indication of the management cover any type of person.
\end{abstract}

Keywords: Impression Management. Graphics. Users.

\title{
RESUMEN
}

Este trabajo tuvo como objetivo verificación de cómo los gráficos con información contábeis puede presentar o no influir en el proceso decisorio de los estudiantes de contabilidad. Foram obtidas 108 respuestas por medio de la aplicación de un cuestionario con gráficos de empresas hipotéticas en los cuales se realizaron gestiones de impresión en la forma de selectividad, melhora de la presentación y distorsión de medidas. Los resultados del estudio evidencian que la gestión de la impresión gráfica influyen en la adopción de la decisión, una vez que las alternativas que presentan estas situaciones se han elegido en el $40 \%$ de los casos. De una manzana general, como características de un individuo no relevante para el resultado, que puede ser un indicador del manejo de cualquier tipo de persona.

Palabras clave: Administración de impresión. Gráficos. Usuarios.

\section{INTRODUÇÃO}

O gerenciamento de impressão corresponde ao processo em que se tenta influenciar a percepção de uma pessoa sobre algo como um objeto ou um evento. $\mathrm{O}$ termo foi proposto por Erving Goffman (1978), numa das obras mais influentes da sociologia moderna, The Presentation of Self in Everyday Life. Em termos dos indivíduos, o gerenciamento de impressão é a tentativa de uma pessoa de apresentar uma imagem aceitável para aqueles que o

Revista Ambiente Contábil - ISSN 2176-9036 - UFRN - Natal-RN. v. 10. n. 1, p. 71 - 87, jan./jun. 2018. 
rodeiam. Neste processo, as pessoas escondem informações que podem entrar em conflito com esta imagem. Um exemplo atual seria um aplicativo de encontros amorosos, no qual as pessoas fazem seu cadastro mostrando o lado mais positivo e escolhendo as suas melhores fotografias. $\mathrm{O}$ termo tem sido amplamente utilizado fora da sociologia, incluindo estudos em diferentes áreas do conhecimento humano, como na política (HALL, 1972), na administração (GIACALONE; ROSENFELD, 2013) ou na medicina (LEWIN; REEVES, 2011).

$\mathrm{O}$ gerenciamento de impressão numa empresa diz respeito à tentativa de se construir uma imagem positiva, influenciando os stakeholders. Existem diferentes formas de se fazer isto, o que inclui as informações produzidas pela contabilidade. A teoria do gerenciamento de impressão pode ajudar a entender o esforço feito pelas empresas na construção da sua imagem e na tentativa de influenciar as pessoas (SPEAR; ROPER, 2013). As empresas podem, por exemplo, tentar influenciar a impressão que externos possuem do desempenho da entidade através do destaque de um determinado índice em lugar de outro. Deste modo, o termo gerenciamento de impressão também se aplica à literatura contábil. O crescimento da parte textual das demonstrações contábeis aumenta a oportunidade deste gerenciamento. De certa forma, o gerenciamento de impressão está associado à evidenciação voluntária da empresa e, segundo Healy e Palepu (2001), esta decisão pode estar motivada por seis forças: transação (percepção que a evidenciação voluntária é relevante para emitir ação ou obter empréstimo ou comprar outra empresa), controle (os gestores usam a evidenciação voluntária para explicar desempenho ruim), compensação (as bonificações por desempenho fornecem incentivos para evidenciação por diversas razões), litígio (possibilidade pode criar incentivos para redução da evidenciação se os gestores acreditam que o sistema legal pode penalizar os atos de gestão), habilidade de sinalização (a evidenciação informa aos investidores que os gestores são talentosos em antecipar as mudanças futuras) e risco (evidenciação vinculada a competição com outras empresas).

Entre as diversas formas de gerenciamento de impressão, esta pesquisa foca sua análise na apresentação gráfica das demonstrações contábeis. Conforme demonstrado por Silva (2016), o número de representações gráficas nos relatórios anuais das empresas abertas brasileiras aumentou substancialmente nos últimos anos: os gráficos apareciam, em média, em uma a cada duas demonstrações contábeis, em 1997; em 2014 eram 3,89 por empresa. Quando computadas as tabelas, ilustrações e fotografias, a média do período passou de 1,58 para 9,13 no período. Assim, os gráficos estão sendo continuamente utilizados pelas empresas. Uma justificativa para esta utilização é o fato de ser um veículo de comunicação fácil e rápido, destacando os aspectos que a administração da empresa julga mais relevante. Por este motivo, o recurso gráfico é um instrumento que pode ser usado para o gerenciamento de impressão por parte da empresa.

Diante do exposto, a pesquisa procura responder o seguinte problema: a forma como os gráficos são apresentados influenciam a decisão dos usuários? Assim, o objetivo desta pesquisa procura verificar se a forma como são apresentados os gráficos com informações contábeis podem (ou não) influenciar o processo decisório dos usuários. Para cumprir este objetivo, a pesquisa optou por focar no gerenciamento de impressão gráfica através da seletividade gráfica, a distorção de medidas e a melhora da apresentação, os três tipos considerados por Bettie e Jones (1992), os autores que são referência na área. A seletividade refere-se à escolha da informação a ser divulgada; a distorção de medida ocorre quando a representação física não é proporcional aos valores; e a melhora da apresentação corresponde a escolha no desenho do gráfico, como formato e linhas desnecessárias.

A justificativa desse estudo pode ser explicada através da pesquisa de Chang et al. (2002) que afirmam que, a maneira como as informações contábeis são apresentadas é capaz de exercer um forte impacto sobre as decisões dos indivíduos e a análise da tomada de 
decisão, no âmbito contábil, pode ter implicações para os contadores no que se refere à elaboração de um formato melhor para evidenciá-los.

Este trabalho está dividido em cinco seções, além desta introdução: a revisão da literatura, onde apresentam trabalhos relacionados com o gerenciamento de impressão gráfica na contabilidade. Em seguida, é descrita a metodologia por meio do qual são descritos os processos utilizados para o desenvolvimento da pesquisa. Na seção posterior, é apresentado o resultado obtido e, por último, são tecidas as considerações finais a respeito do estudo.

\section{GERENCIAMENTO DE IMPRESSÃO NO USO DE GRÁFICOS - ESTUDOS ANTERIORES}

Penteado (2013) afirma que as organizações possuem motivos altruístas para utilizarem gráficos em seus relatórios corporativos, os diagramas são atraentes, despertam atenção através de cores e efeitos visuais, evidenciam tendências e anomalias de forma mais clara. De acordo com Arunachalam et al. (2002), os gráficos são frequentemente utilizados como auxiliares na tomada de decisão, e se utilizados de forma correta podem ser úteis nesse processo. Todavia esse tipo de mecanismo pode ser usado para distorcer as informações que pretendem ser divulgadas para os usuários externos da organização, chegando a transmitir mensagens enviesadas. O fato de os gráficos, em grande parte não serem regulados e auditados contribui para sua utilização para o gerenciamento de impressão (BEATTIE; JONES, 2008)

Alguns estudos vêm sendo realizados no meio acadêmico com uma abordagem sobre o gerenciamento de impressão que podem ser evidenciados pelas empresas ao elaborarem relatórios para os usuários externos à organização. Mohamed, Gardner e Paolillo (1999) afirmam que a introdução de gráficos nos relatórios corporativos reflete a mudança do papel do relatório anual corporativo, tido como um importante documento de relações públicas.

A pesquisa pioneira na área foi de Beattie e Jones (1992) que investigaram o uso ou abuso de gráficos em relatórios financeiros externos de 240 grandes empresas do Reino Unido no ano de 1989. Baseando-se em teorias modernas de percepção gráfica identificaram seletividade na utilização de gráficos, e não conformidade com os princípios de sua construção, como potenciais distorções no processo de comunicação. Os achados revelam que as empresas com "bom" desempenho são significativamente mais propensas a usar gráficos financeiros e que o efeito de distorção de medidas é utilizado para evidenciar um desempenho mais favorável a empresa.

Arunachalam, Pei e Steinbart (2002) relatam os resultados de três experimentos que investigaram os efeitos de gráficos mal desenhados nas escolhas dos sujeitos. Os resultados das três experiências mostram que os gráficos projetados de forma inadequada podem alterar as opções dos sujeitos, refletindo na tomada de decisão. Estes resultados não só têm implicações importantes para a concepção e utilização de gráficos como apoio de decisão, mas também levantam questões políticas potenciais.

Pereira, Fragoso e Ribeiro Filho (2005) compararam o nível de percepção dos usuários de informação contábil das capitais Florianópolis (SC) e Recife (PE) sobre a utilidade de representações gráficas no processo de evidenciação. A pesquisa identificou que existe uma melhor avaliação pelos entrevistados das informações evidenciadas nos demonstrativos contábeis quando são elaborados na própria empresa. Grande parte dos respondentes considerou que a representação gráfica melhora a compreensão das informações contábeis, principalmente em relação à facilidade de visualização para variação de valores.

Lima (2007) verificou se a forma como os relatórios contábeis são elaborados pode ou não influenciar as decisões dos usuários de informação financeira. Os resultados da pesquisa mostraram que os participantes tiveram suas escolhas influenciadas pelo critério de avaliação

Revista Ambiente Contábil - ISSN 2176-9036 - UFRN - Natal-RN. v. 10. n. 1, p. 71 - 87, jan./jun. 2018. 
de estoque e evidenciação de Pesquisa e Desenvolvimento (P\&D) utilizados e também por efeito de inflação na elaboração dos relatórios contábeis, ainda pela utilização de recursos textuais e gráficos na apresentação de relatórios, demonstrando desta maneira o efeito formulação nas situações apresentadas.

Miranda et al. (2008) replicaram o estudo internacional de Beattie e Jones (1992) para verificarem se os relatórios anuais que apresentaram bom desempenho financeiro utilizaram gráficos de uma forma diferente, em relação aos relatórios que apresentam prejuízo. O estudo revelou que relatórios com situação lucrativa apresentam gráficos com variáveis diferentes dos que apresentam prejuízos. A pesquisa ainda revela que os relatórios que apresentam lucro menor que o do ano anterior tendem a apresentar gráficos adicionais para explicar as causas de redução do resultado.

Jones (2011b) investigou o uso de gráficos em relatórios sociais e ambientais, especificamente os relatórios de sustentabilidade divulgados por 63 empresas do Reino Unido. Os resultados mostram que os gráficos são amplamente utilizados, mas não há evidência clara de gerenciamento de impressão, porém foram utilizados de forma seletiva e distorcida, de modo a dar uma visão mais favorável da empresa, indicando uma preferência pela utilização de gráficos que dão destaque a informações favoráveis, em detrimento de informações negativas.

Penteado (2013) por sua vez, realizou um estudo que investigou se os gráficos apresentados nos relatórios de sustentabilidade publicados por cinquenta empresas brasileiras de capital aberto foram utilizados como ferramenta para o gerenciamento de impressões. Os resultados da pesquisa evidenciaram que apesar da predominância de utilização de gráficos para notícias positivas e das distorções de medidas físicas identificadas, as evidências mostram que a interpretação de tais resultados decorre de um desespero ou desatenção dos responsáveis pelo relatório de sustentabilidade.

Nascimento et al. (2013) identificaram o emprego de recursos visuais nos relatórios de administração das empresas brasileiras analisando a influência dos gráficos na neutralidade de informações apresentadas. A pesquisa concluiu que com o passar dos anos a utilização desses recursos visuais foi aumentando, contudo, os tipos de gráficos exibidos não sofreram variações, os que utilizam colunas foram os mais empregados. A pesquisa ainda evidenciou que uma parcela dos diagramas pode dar margem a interpretação indevida em consequência de técnicas empregadas em sua elaboração

Silva (2016) fez a mais ampla pesquisa brasileira sobre o assunto, pesquisando 180 empresas com capital aberto no período de 1997 a 2014. Usando um modelo econométrico, a autora mostrou a existência de relação entre a quantidade de gráficos e informações financeiras-chave (lucro líquido, receita e dividendos), assim como a relação com o gerenciamento de impressão nos gráficos. Outro resultado obtido pela autora foi a existência de relação entre a idade da empresa e o gerenciamento.

A análise das pesquisas realizadas na área permite classificá-las em dois grandes grupos. No primeiro, estão as investigações sobre a presença ou não de gerenciamento de impressão gráfica nos relatórios publicados pelas empresas, como é o caso do trabalho pioneiro de Beattie e Jones (1992) ou da pesquisa mais recente, no Brasil, de Silva (2016). Neste grupo de pesquisa o foco é verificar a existência de gráficos com gerenciamento de impressão e, eventualmente, testar a existência de alguma relação com a característica da empresa ou da informação divulgada. No segundo grupo estão as investigações sobre o efeito do gerenciamento nas decisões, como é o caso da pesquisa de Lima (2007) e de Arunachalam, Pei e Steinbart (2002). Conforme será detalhado a seguir, a pesquisa apresentada aqui faz parte do segundo grupo. Ao contrário destas pesquisas citadas, a proposta dos autores está focada no tipo de gerenciamento de impressão, a saber, seletividade, distorção de medidas e melhora da apresentação, conforme será detalhado no item a seguir. 


\section{PROCEDIMENTOS METODOLÓGICOS}

Foi elaborado um questionário (ver Apêndice) com a intenção de verificar se a forma como os gráficos com informações contábeis é apresentada pode ou não influenciar o processo decisório. O questionário foi validado através de uma análise crítica feita por terceiros. Uma primeira versão do questionário foi aplicada, mas em razão de um erro de impressão, as respostas foram consideradas invalidadas pelos autores. Outro questionário corrigido foi aplicado após a correção do erro.

As perguntas foram realizadas com 111 respondentes, sendo que os questionários foram aplicados no Distrito Federal (29 do total de respondentes), Pernambuco (63) e Rio de Janeiro (19), de forma presencial, entre os meses de março a maio de 2016. Estes locais foram escolhidos pela acessibilidade dos pesquisadores. Ademais, buscou aplicar o questionário em vários locais do País para permitir uma melhor abrangência dos resultados. A aplicação dos questionários concentrou-se em sala de aula; entretanto, não estudantes também participaram da pesquisa e correspondem a $49 \%$ da amostra.

Dentre os respondentes, 3 deles não responderam as questões relativas ao gerenciamento de impressão, ficando a amostra final, com 108 questionários respondidos. Acredita-se que esta amostra seja constituída de pessoas com uma certa familiaridade com gráficos, muito embora não sejam especialistas em gerenciamento de impressão. Também acredita-se que este público corresponda, aproximadamente, ao usuário comum das demonstrações contábeis, com um grau de conhecimento da informação que estava sendo apresentada. Vale ressaltar que todos os estudantes ou estavam cursando ou já tinham cursado disciplinas que fornecessem subsídios para a escolha de investimentos.

Cada questionário é composto por três blocos de perguntas: no primeiro, foram apresentadas questões acerca das características pessoais dos respondentes, tais como escolaridade, renda mensal, idade e gênero. O objetivo desse bloco foi traçar alguma relação entre essas características e a influência (ou não) do gerenciamento de impressão nas decisões de investimentos. No segundo bloco havia questões sobre o tipo de investimento que os mesmos realizam, qual o valor dispendido nos investimentos e qual o nível de conhecimento sobre decisões de investimentos eles acreditam ter. O objetivo com a inserção desse bloco de questões no questionário foi de relacionar o grau de conhecimento e a experiência em investimento com a possível influência do gerenciamento de impressão. Por fim, no último bloco havia cinco perguntas com gráficos de empresas hipotéticas nos quais os respondentes deveriam escolher em qual empresa eles investiriam. Em todos os gráficos foram utilizados algum tipo de gerenciamento de impressão presente na literatura: o primeiro e o terceiro gráfico apresentavam distorção nas medidas; o segundo e o quinto apresentavam melhora na apresentação; e o quarto apresentava seletividade.

Com relação à pergunta 12, o tipo de gerenciamento de impressão utilizado foi o da distorção de medidas: os gráficos das empresas " $A$ " e " $B$ " apresentavam os mesmos valores, contudo, em decorrência do ajuste na escala do gráfico, a empresa " $A$ " apresentava menor volatilidade dos lucros. Em decorrência disso, escolher a opção da empresa "A" indicava o gerenciamento de impressão; se a escolha do respondente fosse o gráfico da empresa "B", seria neutro ao gerenciamento; escolhendo as duas, não seria influenciado.

$\mathrm{Na}$ questão 13, o gerenciamento de impressão utilizado foi a da melhora na apresentação: como a empresa "ABC" apresentou retorno sobre o investimento menor que a empresa "DEF", o gráfico da primeira foi ajustado de forma que beneficiasse a sua apresentação. Ao escolher a empresa "ABC" como forma de investimento, o respondente 
estaria sendo influenciado pelo gerenciamento de impressão; se escolhesse a empresa "DEF" o estudante não seria influenciado e; ao escolher as duas, haveria neutralidade.

A questão 14 também exibia distorção de medidas: a empresa "Alfa" apresentava um lucro líquido superior ao da empresa "Ômega", contudo, o gráfico da "Alfa" estava em reais/mil e o da "Ômega" estava em reais, o que conduz a interpretação de que a volatilidade do lucro líquido seja menor nesta última. Se o respondente escolhesse a empresa "Alfa", ele não seria influenciado pelo gerenciamento de impressão; se escolhesse a "Ômega" seria influenciado e; se escolhesse as duas, haveria neutralidade.

Já na pergunta 15, o modelo de gerenciamento de impressão escolhido foi o da seletividade: as empresas "Sinos S.A." e "Luzes S.A." apresentavam os mesmos valores investidos em projetos ambientais. Contudo, a "Luzes S.A." o apresentou somente a partir de 2011, com o intuito de indicar somente crescimento nesse investimento. Se fosse analisado desde 2009, como é o caso da empresa "Sinos S.A.", haveria a percepção de queda no investimento. Dessa forma, se o respondente escolhesse a empresa "Sinos S.A.", seria neutro; se escolhesse a "Luzes S.A.", o mesmo estaria sendo influenciado pelo gerenciamento e; se escolhesse as duas opções, não estaria sendo influenciado.

Por fim, na questão 16, a melhora na apresentação do gráfico da empresa "Raio da Manhã S.A.” faz com que não se perceba a queda no lucro líquido, diferentemente da empresa "Luz do Sol S.A.". Se a opção escolhida fosse a empresa "Luz do Sol S.A.", o respondente não seria influenciado pelo gerenciamento de impressão; se escolhesse a empresa "Raio da Manhã S.A.”, estaria sendo influenciado e; se escolhesse ambas, haveria a neutralidade. Um resumo das opções consta no quadro 1.

Quadro 1: Resumo das opções de escolhas de gerenciamento de impressão

\begin{tabular}{|l|l|l|l|l|l|}
\hline $\begin{array}{l}\text { Questões/Opçõ } \\
\text { es }\end{array}$ & \multicolumn{1}{|c|}{$\begin{array}{c}\text { Questão } \\
12\end{array}$} & Questão 13 & Questão 14 & Questão 15 & Questão 16 \\
\hline $\begin{array}{l}\text { Com } \\
\text { gerenciamento }\end{array}$ & $\begin{array}{l}\text { Empresa } \\
\text { A }\end{array}$ & $\begin{array}{l}\text { Empresa } \\
\text { ABC }\end{array}$ & $\begin{array}{l}\text { Empresa } \\
\text { Ômega }\end{array}$ & $\begin{array}{l}\text { Empresa } \\
\text { Luzes }\end{array}$ & $\begin{array}{l}\text { Empresa } \\
\text { Raio da } \\
\text { Manhã }\end{array}$ \\
\hline $\begin{array}{l}\text { Sem } \\
\text { gerenciamento }\end{array}$ & As duas & $\begin{array}{l}\text { Empresa } \\
\text { DEF }\end{array}$ & Empresa Alfa & As duas & $\begin{array}{l}\text { Empresa Luz } \\
\text { do Sol }\end{array}$ \\
\hline Neutra & $\begin{array}{l}\text { Empresa } \\
\text { B }\end{array}$ & As duas & As duas & $\begin{array}{l}\text { Empresa } \\
\text { Sinos }\end{array}$ & As duas \\
\hline
\end{tabular}

Fonte: Elaborado pelos autores.

Para o tratamento e análise quantitativa dos dados utilizou-se a estatística quiquadrado de Pearson, um teste não-paramétrico que busca identificar associações significativas entre variáveis categóricas, e o teste de duas proporções, conforme será detalhado no próximo item. Caso o nível de significância seja pequeno $(<0,05)$, rejeita-se a hipótese nula de que as variáveis são independentes e assume-se que, de alguma maneira, elas são relacionadas. Apesar de adotar este nível de significância, os autores destacam neste trabalho resultados que ficaram próximos deste valor.

Entre as características do respondente analisadas na pesquisa tem-se a idade, o fato de ser ou não estudante, a renda familiar, o tipo de investimento realizado (poupança, mercado acionário etc.), se o volume investido é elevado ou não, a característica primordial na escolha do investimento e se conhece ou não finanças. Este aspecto também será destacado no próximo item. 


\section{ANÁLISE DOS RESULTADOS}

O respondente típico era jovem, com idade entre 21 a 25 anos (59\% da amostra), estudante $(51 \%)$, com renda familiar de até 5 mil reais $(67 \%)$, homem (52\%), com investimento principalmente na caderneta de poupança $(47 \%)$. A preferência por este investimento é reflexo da busca por segurança (67\%), considerado o item mais relevante para a decisão de investimento. Aqueles que declararam possuir investimentos acima de dez mil reais representam 35\% da amostra. Finalmente, o conhecimento em finanças esteve dividido entre pouco (45\%) e razoável (39\%), sendo evitado respostas extremas (nenhum ou muito).

Dentre as questões que faziam parte do questionário, 5 delas correspondiam ao terceiro e último bloco no qual cada uma possuía dois gráficos de empresas hipotéticas e os respondentes deveriam escolher em qual empresas eles investiram, de acordo os dados que estavam sendo apresentados. Na Tabela 1 segue as decisões dos respondentes.

Tabela 1: Decisões dos respondentes sobre as opções de investimento

\begin{tabular}{|c|c|c|c|c|}
\hline $\begin{array}{l}\text { Questões / } \\
\text { Respostas }\end{array}$ & $\begin{array}{l}\text { Opção com } \\
\text { gerenciamento }\end{array}$ & $\begin{array}{c}\text { Opção sem } \\
\text { gerenciamento }\end{array}$ & Neutra & Total \\
\hline Questão 12 & $55 \%$ & $30 \%$ & $15 \%$ & $100 \%$ \\
\hline Questão 13 & $28 \%$ & $31 \%$ & $41 \%$ & $100 \%$ \\
\hline Questão 14 & $45 \%$ & $37 \%$ & $18 \%$ & $100 \%$ \\
\hline Questão 15 & $60 \%$ & $19 \%$ & $21 \%$ & $100 \%$ \\
\hline Questão 16 & $10 \%$ & $72 \%$ & $18 \%$ & $100 \%$ \\
\hline Total & $40 \%$ & $38 \%$ & $22 \%$ & $100 \%$ \\
\hline
\end{tabular}

Fonte: Elaborada pelos autores.

De uma maneira geral, pode-se observar que a maioria dos respondentes (40\%) escolheram a opção de investimento com o gerenciamento de impressão, conforme elucidado em pesquisas anteriores, como as de Arunachalam et al. (2002) e Lima (2007). Como em cada uma das perguntas existiam respostas corretas, o fato de uma parcela da amostra ter optado pela alternativa com gerenciamento já é uma comprovação que esta técnica possui um efeito sobre a decisão das pessoas. Este primeiro resultado indica a existência do efeito do gerenciamento: afinal, indivíduos totalmente racionais não seriam "enganados" pelo gerenciamento de impressão gráfico.

Uma análise comparativa da coluna "com gerenciamento" versus a coluna "sem gerenciamento" revela algo mais: em três questões $(12,14$ e 15) o percentual de escolha foi maior no primeiro caso do que no segundo. A partir das respostas foi realizado um teste para verificar se a escolha entre "com gerenciamento" e "sem gerenciamento" é estatisticamente diferente do mero acaso. Para isto, utilizou-se o teste de proporções, comparando a proporção com gerenciamento, em relação a soma das respostas não neutras, com o resultado que seria obtido caso o respondente escolhesse qualquer uma das alternativas, ou seja, uma proporção de 50\%. Este teste serve para demonstrar não somente que o gerenciamento de impressão de gráficos funciona, como o seu resultado pode ser estatisticamente diferente de uma escolha aleatória.

O resultado obtido indicou que as duas últimas questões apresentaram um p-valor de zero, usando três casas decimais. Ou seja, na questão 15 o gerenciamento de impressão fez diferença no resultado, distorcendo a decisão; e na questão 16 não houve influência sobre a decisão, já que a proporção que escolheu a alternativa com gerenciamento foi inferior aos que escolheram a alternativa sem gerenciamento. A questão 12 apresentou um p-valor de 0,053 , um resultado próximo ao critério de decisão geralmente usado em ciências sociais, que é de

Revista Ambiente Contábil - ISSN 2176-9036 - UFRN - Natal-RN. v. 10. n. 1, p. 71 - 87, jan./jun. 2018. 
0,05. Para os demais casos, as diferenças nos resultados obtidos na pesquisa não podem ser considerados estatisticamente diferentes. Assim, este segundo resultado permite concluir que o gerenciamento funciona, na medida em que parte da amostra optaram por fazer escolhas induzidas; e que em dois dos cinco casos, o gerenciamento foi significativamente diferente de uma escolha aleatória.

Usando os mesmos dados do teste anterior, ou seja, somente as respostas "com" versus "sem" gerenciamento, analisou-se se o perfil do respondente tinha algum efeito sobre o resultado. Aqui, a pesquisa faz um confronto entre as respostas das questões 12 a 16 e as respostas das questões anteriores. As características analisadas são as seguintes:

a) Jovem - a partir das respostas obtidas, segregou a amostra nos respondentes jovens, considerando como tal aqueles com até 25 anos. A princípio acredita-se que os respondentes mais jovens possam evitar mais o gerenciamento de impressão por estarem mais acostumados com a informação visual. Conforme mostra Silva (2016), o número de informações visuais nos relatórios contábeis brasileiros cresceu substancialmente nos últimos anos. Por outro lado, o respondente mais jovem possui menos experiência no processo decisório, podendo ser mais influenciável à informação disponibilizada.

b) Estudante - como um pouco mais da metade da amostra era constituída por estudantes, tentou-se verificar se este fato poderia influenciar os resultados. Muitas pesquisas usam como amostra os estudantes em razão da acessibilidade e supondo que não haverá diferença nos resultados apurados. Acredita-se, a priori, que o gerenciamento de impressão gráfica não seja influenciado por esta variável.

c) Renda familiar - a pergunta sobre a renda familiar pode ser uma proxy também para nível de escolaridade e acesso a informação. Assim, espera-se que quanto maior a renda, menor a chance de gerenciamento de impressão. Entretanto, este dado pode ser influenciado pela localização dos respondentes, já que a renda familiar depende do poder de compra da moeda. Os respondentes foram divididos em dois grupos: aqueles com renda familiar abaixo de $\mathrm{R} \$ 3$ mil ( $41 \%$ da amostra) e os que possuem uma renda superior a este valor.

d) Poupança - A pergunta sobre o tipo de investimento que o respondente faz revelou uma grande concentração na caderneta de poupança. Como este é uma aplicação com reduzida sofisticação, acredita-se que exista uma relação direta entre aqueles que fazem este investimento e o gerenciamento de impressão.

e) Valor Investido - foi solicitado o volume de recursos investidos pelo respondente. Do total, 23 respondentes afirmaram ter mais de 10 mil reais investidos. A suposição a priori é que pessoas com maiores recursos aplicados sejam menos passíveis ao gerenciamento de impressão.

f) Segurança - entre as características da aplicação, a segurança mereceu o destaque de 59 respondentes. Assim, este tópico foi analisado em separado, podendo ser considerado uma proxy de conservadorismo nas decisões financeiras.

g) Conhecimento - a pergunta sobre o grau de conhecimento, segundo a opinião do respondente, sobre investimento, revelou que $54 \%$ afirmaram ter pouco ou nenhum conhecimento. Poderia existir, a priori, uma relação entre o grau de conhecimento e o gerenciamento de impressão, em que pese o efeito Lake Wobegon. 
h) Gênero - pretende verificar se o gênero interfere nos resultados obtidos. Não existe, a priori, uma expectativa com respeito ao resultado.

Como foram feitas cinco questões sobre gerenciamento e avaliadas oito variáveis, isto resulta em quarenta testes para verificar se as características do respondente, elencadas anteriormente, afetaram os resultados. Usando 5\% de nível de significância como parâmetro, somente três testes revelaram significância, sendo mais um apresentou um p-valor de 0,0597, um pouco acima do parâmetro estabelecido. A expansão do nível para $10 \%$ não acrescenta nenhum resultado dos testes realizados. Este terceiro resultado permite afirmar que as características do respondente não influem nos resultados, com estas quatro exceções.

A questão 14, que trata da distorção de medida, apresentou relação com a busca por segurança no investimento realizado. O resultado mostrou um qui-quadrado de 5,637, com um $p$-valor de 0,018. Assim, que indicou a segurança como principal motivador na escolha de um investimento também fez opção pela alternativa com gerenciamento de impressão. A busca pela segurança talvez seja um indício que a o indivíduo não se sinta preparado para escolher graficamente entre duas empresas.

A questão 15 tratou da seletividade. Os respondentes com baixo nível de investimento foram iludidos pelo gerenciamento, como era esperado a priori. O qui-quadrado obtido foi de 6,155, com um p-valor de 0,013, indicando a presença de relação entre a escolha as variáveis. Este resultado foi o melhor obtido pela pesquisa em termos da significância.

A terceira relação a ser analisada refere-se a resposta da questão 12 , sobre distorção de medidas, e o fato do respondente ser jovem. O resultado obtido apontou um qui-quadrado de 3,544, com um p-valor um pouco acima do nível de significância, de 0,0597, conforme informado anteriormente. Relaxando o nível de significância, isto indicaria que os jovens sofreram influência do gerenciamento.

Mais importante que estes três resultados obtidos são os resultados que não apresentaram significância. Com efeito, 37 testes mostraram um p-valor acima de 0,10. As variáveis estudante (versus não estudante), renda familiar, poupança, valor investido, conhecimento e gênero não apresentaram nenhum resultado. Este resultado é poderoso, na medida em que talvez seja possível afirmar que o gerenciamento aproveita de uma falha mental do ser humano, que independe destas características. Mesmo as três variáveis onde se obteve resultados representativos, conforme relatado nos três últimos parágrafos, é importante notar que isto foi uma exceção, não uma regra.

\section{CONSIDERAÇÕES FINAIS}

Em meio ao crescente número de gráficos nos relatórios contábeis, este estudo buscou verificar se a forma como os gráficos com informações contábeis é apresentada influencia ou não na decisão de investimentos. Para o alcance do objetivo, foi aplicado um questionário no qual havia gráficos de empresas hipotéticas nos quais os respondentes deveriam escolher em qual empresa investiriam. Pelo menos um dos gráficos de cada questão possuía algum tipo de gerenciamento de impressão, seja ele na forma de seletividade, melhora na apresentação ou distorção de medidas.

O questionário foi respondido por 108 pessoas, sendo possível verificar, através da estatística de qui-quadrado, que a proporção de respostas a uma alternativa é significativamente diferente da proporção da outra. Numa situação ideal, de racionalidade plena das pessoas, os gráficos com gerenciamento não seriam escolhidos ou a resposta seria pela indiferença. Entretanto, na média, $40 \%$ das respostas escolhidas foram para as alternativas com gerenciamento de impressão gráfica, versus $38 \%$ sem gerenciamento e o

Revista Ambiente Contábil - ISSN 2176-9036 - UFRN - Natal-RN. v. 10. n. 1, p. 71 - 87, jan./jun. 2018. 
restante para opção neutra. Considerando somente as duas primeiras alternativas, as respostas para as alternativas com gerenciamento ultrapassam a mais da metade. O teste de proporção mostrou que em alguns casos as escolhas realizadas ultrapassam o mero "acaso" de escolher uma das alternativas. Os resultados obtidos estão na linha da literatura, que tem destacado a influência do gerenciamento no processo decisório, conforme demonstrado no item dois deste texto.

Adicionalmente, testou a existência de influência das características dos indivíduos nas respostas. Dos testes realizados, somente 3 apresentaram significância, um valor bastante reduzido. Isto seria um possível indicativo de que o gerenciamento não faz distinção entre as pessoas.

O trabalho realizado possui diversas limitações que podem restringir a conclusão obtida com a amostra usada. Em primeiro lugar, a amostra é sempre uma restrição; para este caso, recomenda-se a replicação com amostras diferentes e em locais diferentes. Em segundo lugar, o questionário e a ordem das questões podem ter influência sobre os resultados. Terceiro, apesar dos cuidados sempre presente neste tipo de pesquisa, a forma de aplicação pode ter influência sobre o resultado.

Como trabalhos futuros, recomenda-se o aumento da amostra observada em outras regiões do país para verificar se é encontrado o mesmo resultado, ou ainda diversificar a análise para outros tipos de respondentes. Outra alternativa para pesquisa é modificar a figura apresentada: isto pode ter influência no resultado. Finalmente, e em consonância com Benartzi e Lehrer (2015), a aplicação em ambiente virtual seria importante e interessante para comprovar a influência do gerenciamento no mundo conectado.

\section{REFERÊNCIAS}

ARUNACHALAM, V; PEI, B.K.W.; STEINBART, P.J. Impression management with graphs: effects on choices. Journal of Information Systems. V. 16, n. 2, p. 183-202, 2002.

BEATTIE, V.; JONES, M. J. The use and abuse of graphs in anual reports: a theoretical framework and empirical study. Accounting and Business Research, v. 22, n. 88, p. 291303, 1992.

BEATTIE, V.; JONES, M. J. Corporate reporting using graphs: a review and synthesis. Journal of Accounting Liteature, v. 27, p. 71-110, 2008.

BENARTZI, Shlomo; LEHRER, Jonah. The Smarter Screen: What Your Business Can Learn from the Way Consumers Think Online. Hachette UK, 2015.

CHANG, C. Janie; YEN, Sin-Hui; DUH, Rong-Ruey. An empirical examination of competing theories to explain the framing effect in accounting - related decisions. Behavioral Research in Accounting, v. 14, p. 35-64, 2002.

GIACALONE, Robert A.; ROSENFELD, Paul (Ed.). Impression management in the organization. Londres: Thomson, 2013.

GOFFMAN, Erving et al. The presentation of self in everyday life. Londres: Harmondsworth, 1978.

HEALY, Paul M.; PALEPU, Krishna G. Information asymmetry, corporate disclosure, and the capital markets: a review of the empirical disclosure literature. Journal of Accounting and Economics, 31, p. 405-440, 2001.

JONES, M. J. Creative accounting, frauds and international accounting scandals. England: John Wiley and Sons Ltd, 2011a.

Revista Ambiente Contábil - ISSN 2176-9036 - UFRN - Natal-RN. v. 10. n. 1, p. 71 - 87, jan./jun. 2018. 
JONES, M. J. The Nature, use and impression management of graphs in social and environmental accouting. Accounting forum, v. 35, n.2,p. 75-89, 2011 b.

LEWIN, Simon; REEVES, Scott. Enacting 'team'and 'teamwork': Using Goffman's theory of impression management to illuminate interprofessional practice on hospital wards. Social Science \& Medicine, v. 72, n. 10, p. 1595-1602, 2011.

LIMA, Diogo Henrique Silva de. Efeito da Formulação e Contabilidade: uma análise da influência da forma de apresentação de demonstrativos e relatórios contábeis sobre o processo decisório de usuários de informações contábeis. 2007. 143f. Dissertação (Mestrado do Programa Multiinstitucional e Inter-Regional de Pós-Graduação em Ciências Contábeis) (UNB-UFPB-UFPE-UFRN). Natal, 2007.

MIRANDA, L.C.; VIEIRA, A. S.; LAGIOIA, U.C.T.; VASCONCELOS, M.T.C. Utilização de gráficos em demonstrações contábeis. Revista de Educação e Pesquisa em Contabilidade, v. 2, n. 3, p. 16-35, 2008.

MOHAMED, A. A.; GARDNER, W. L.; PAOLILLO, J. G. P. A taxonomy of organizational impression management tactics. Advances in Competitiveness Research, v. 7, n. 1, p. 108130, 1999.

NASCIMENTO, M.D.; RODRIGUES, F.F.; ALBUQUERQUE, P.H.M.; SILVA C.A.T. Gerenciamento da apresentação: uma análise da utilização de gráficos nos relatórios da administração. Revista Universo Contábil, v. 9, n. 1, p.46-64, 2013

PEREIRA, C.C.; FRAGOSO, A.R.; RIBEIRO FILHO, J.F. Comunicação em Contabilidade: estudo comparative do nível de percepção dos usuários da informação contábil em Florianópolis (SC) e Recife (PE) sobre a utilidade das representações gráficas no processo de evidenciação. Revista Brasileira de Contabilidade, n. 156, p. 51-69, 2005.

PENTEADO, Isabela Alves de Morais. Gerenciamento de impressão em relatórios de sustentabilidade no Brasil: uma análise do uso de gráficos. 2013. 108p. Dissertação (Mestrado em Controladoria e Contabilidade) - Faculdade de Economia, Administração e Contabilidade de Ribeirão Preto, Universidade de São Paulo, São Paulo, 2013.

PONTE, V. M. R.; OLIVEIRA, M. C. de; MOURA, H. J. de; BARBOSA, J. V. Análise das metodologias e técnicas de pesquisas adotadas nos estudos brasileiros sobre Balanced Scorecard: um estudo dos artigos publicados no período de 1999 a 2006. In: I Congresso ANPCONT. Anais. Gramado/RS. 2007.

SILVA, Keylla Dennyse Celestino da. Gerenciamento de impressão: uma análise sobre a utilização de recursos gráficos nos relatórios de companhias abertas brasileiras. 103f. Dissertação (Mestrado do Programa Multiinstitucional e Inter-Regional de Pós-Graduação em Ciências Contábeis) (UNB-UFPB-UFRN). Brasília, 2016.

SPEAR, Sara; ROPER, Stuart. Using corporate stories to build the corporate brand: an impression management perspective. Journal of Product \& Brand Management, v. 22, n. 7, p. 491-501, 2013.

\section{APÊNDICE}

Prezado (a) Estudante,

Você está sendo convidado (a) participar de uma pesquisa sobre decisões de investimentos. Nela, estamos buscando identificar possíveis motivos que induzem os profissionais contábeis a escolher determinada empresa para investir em detrimento de outra. 
Você será submetido a um instrumento de pesquisa contendo três etapas: na primeira são apresentadas afirmativas que procuram identificar características pessoais, como sexo, grau de escolaridade; na segunda etapa são apresentadas questões sobre decisão de investimento e; na terceira e última etapa, questões nas quais os respondentes deverão optar por qual tipo de investimento eles escolhem realizar.

Em nenhum momento você será identificado. Os resultados da pesquisa serão publicados e ainda assim a sua identidade será preservada. Você não terá nenhum gasto e ganho financeiro por participar na pesquisa. Os benefícios serão o oferecimento de dados sobre as decisões de investimento, contribuindo para o estudo acerca das possíveis influências do gerenciamento de impressão nessas escolhas.

Obrigada pela participação!

Dados Pessoais:

A seguir são apresentadas questões pessoais, como sexo, grau de escolaridade, faixa salarial, dentre outros. Em nenhum momento haverá questões que tornem possível a sua identificação.

1) Qual a sua idade?

( ) Entre 18 e 20 anos

( ) Entre 21 e 25 anos

( ) Entre 26 e 30 anos

( ) Entre 31 e 35 anos

( ) Mais de 35 anos

2) Qual o seu nível de escolaridade?

( ) Ensino técnico

( ) Bacharel em Ciências Contábeis

( ) Mestre em Ciências Contábeis

( ) Doutor em Ciências Contábeis

( ) Outro: especificar:

3) Qual o seu ramo de atuação:

( ) Estudante

( ) Profissional liberal / autônomo

( ) Profissional da área privada

( ) Servidor do munícipio, estado ou federação

( ) Professor

( ) Outro: especificar:

4) Em média, quanto é a sua renda familiar mensal?

( ) Menor que $\mathrm{R} \$ 1.000,00$

( ) Entre $\mathrm{R} \$ 1.000,01$ e $\mathrm{R} \$ 3.000,00$

( ) Entre R\$3.000,01 e R \$5.000,00

( ) Entre $\mathrm{R} \$ 5.000,01$ e $\mathrm{R} \$ 7.000,00$

( ) Maior que $\mathrm{R} \$ 7.000,01$

5) Você se considera de qual gênero?

( ) Masculino

( ) Feminino

( ) Outros

Revista Ambiente Contábil - ISSN 2176-9036 - UFRN - Natal-RN. v. 10. n. 1, p. 71 - 87, jan./jun. 2018. 
Tipos de Investimentos:

Nessa seção, serão apresentadas questões sobre os tipos de investimentos que realiza e qual o montante dispendido, bem como acerca do nível de conhecimento em decisões de investimento.

6) Qual o tipo de investimento que você realiza? (Caso realize mais de um investimento, favor marcar todas as opções que efetua):

( ) Não realizo investimentos

( ) Poupança

( ) Títulos públicos

( ) Ações

( ) CDB's e RDB's

( ) Clubes de Investimento

( ) Imóvel

( ) Outros: especificar:

7) Caso tenha respondido que não realiza investimentos na questão 6, por qual motivo não o realiza?

( ) Falta de conhecimento sobre as opções de investimentos

( ) Falta de tempo para dedicar-se a investir

( ) No momento, não possui recursos suficientes

( ) Falta de interesse

( ) Outros: especificar:

8) Caso tenha respondido na questão 6 que realiza algum tipo de investimento, há quanto tempo o realiza?

( ) Menos de 1 ano

( ) Entre 1 ano e 2 anos

( ) Entre 2 anos e 5 anos

( ) Mais de 5 anos

9) Em média, quanto que você possui de investimento?

( ) Menos de R $\$ 2.000,00$

( ) Entre R \$2.000,01 e R \$5.000,00

( ) Entre R $\$ 5.000,01$ e $\mathrm{R} \$ 8.000,00$

( ) Entre R $\$ 8.000,01$ e R $\$ 10.000,00$

( ) Mais de $\mathrm{R} \$ 10.000,00$

10) Quando opta por algum tipo de investimento, o que mais lhe atrai?

( ) Rentabilidade alta

( ) Segurança alta

( ) Desconto no Imposto de Renda

( ) Outros: especificar:

11) Em sua opinião, com relação a decisões de investimento, marque a opção que melhor se adeque ao seu nível de conhecimento:

( ) Não possuo conhecimento

( ) Possuo pouco conhecimento

( ) Possuo conhecimento razoável

( ) Possuo bom conhecimento

Revista Ambiente Contábil - ISSN 2176-9036 - UFRN - Natal-RN. v. 10. n. 1, p. 71 - 87, jan./jun. 2018. 
Mariana Pereira Bonfim, Ilka Gislayne de Melo Souza, César Augusto Tibúrcio Silva e Alex de Oliveira Serafim

( ) Possuo total conhecimento

Opções de Investimentos:

A seguir, serão apresentados dados de empresas distintas e você deverá escolher em qual delas irá investir, com base em seus conhecimentos sobre investimentos e considerando que você possua renda suficiente para escolher qualquer uma das opções.

12) A partir dos dados das empresas "A" e "B" abaixo, em qual (is) delas você investiria, baseado naquela que possui o menor risco?

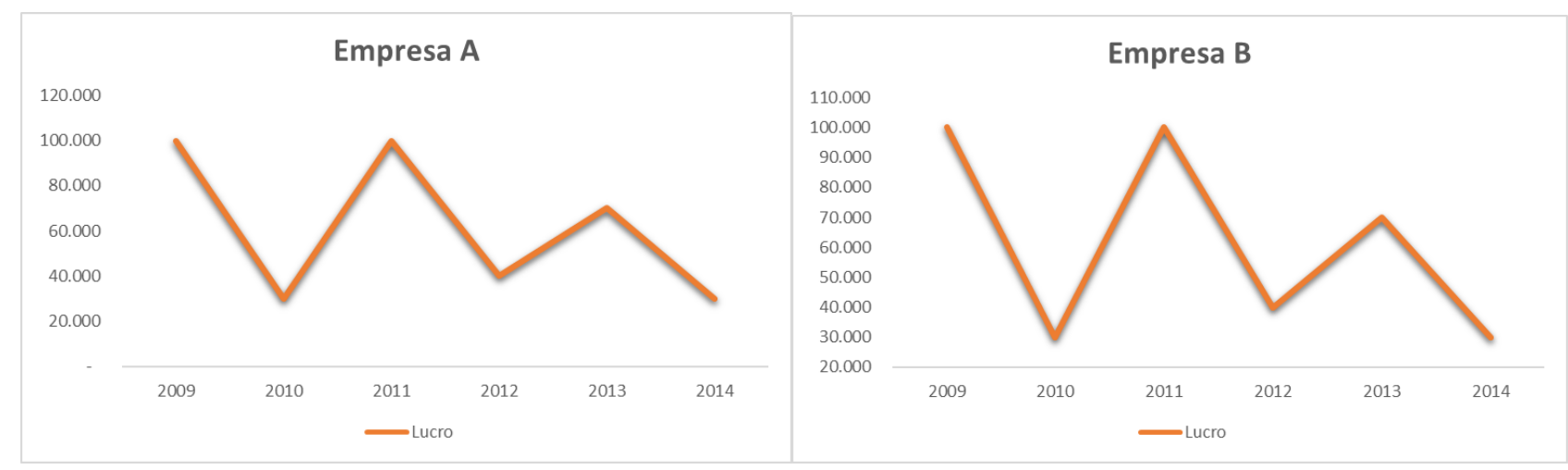

( ) Empresa A

( ) Empresa B

( ) As duas empresas

13) A partir dos dados das empresas "ABC" e "DEF" abaixo, em qual (is) delas você investiria, baseado na que possui o melhor retorno sobre o investimento?

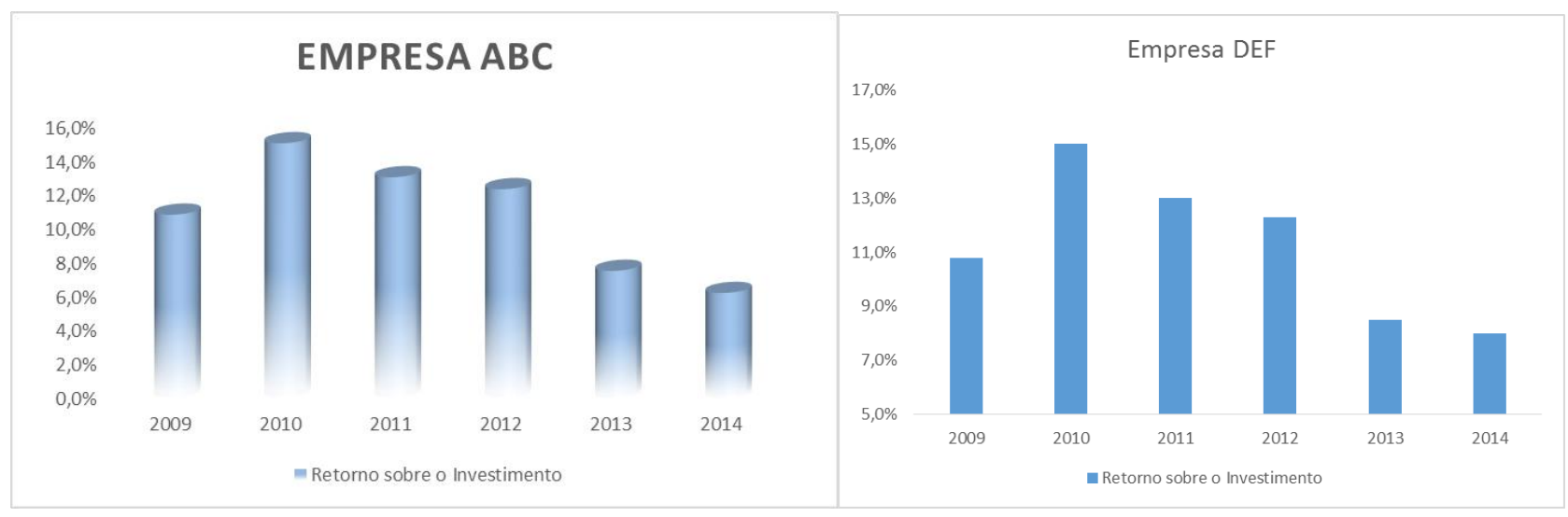

( ) Empresa ABC

( ) Empresa DEF

( ) As duas empresas

Revista Ambiente Contábil - ISSN 2176-9036 - UFRN - Natal-RN. v. 10. n. 1, p. 71 - 87, jan./jun. 2018. 
14) A partir dos dados das empresas "Alfa" e "Ômega" abaixo, em qual (is) delas você investiria, baseado naquela que possui a maior lucratividade?

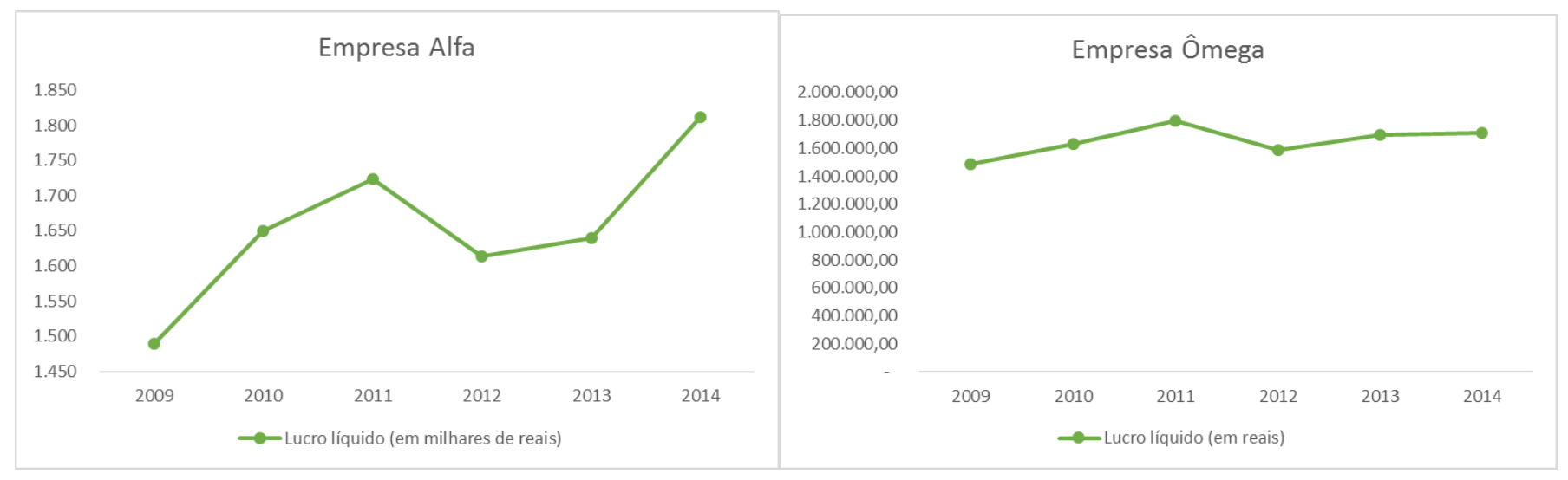
( ) Empresa Alfa
( ) Empresa Ômega
( ) As duas empresas

15) A partir dos dados das empresas "Sinos S.A." e "Luzes S.A." abaixo, em qual (is) delas você investiria, baseado naquela que possui o melhor investimento em projetos ambientais?

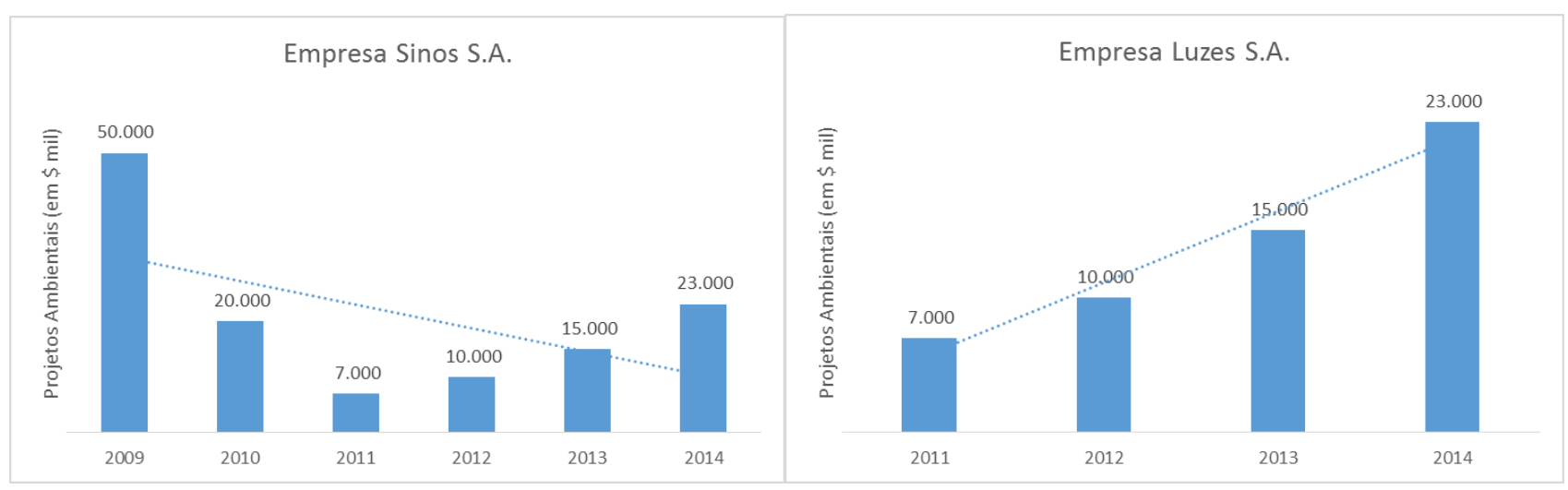
( ) Empresa Sinos S.A.
( ) Empresa Luzes S.A.
( ) As duas empresas 
Mariana Pereira Bonfim, Ilka Gislayne de Melo Souza, César Augusto Tibúrcio Silva e Alex de Oliveira Serafim

16) A partir dos dados das empresas "Luz do Sol S.A." e "Raio da Manhã S.A." abaixo, em qual delas você investiria, baseado naquela que possui a melhor receita líquida?

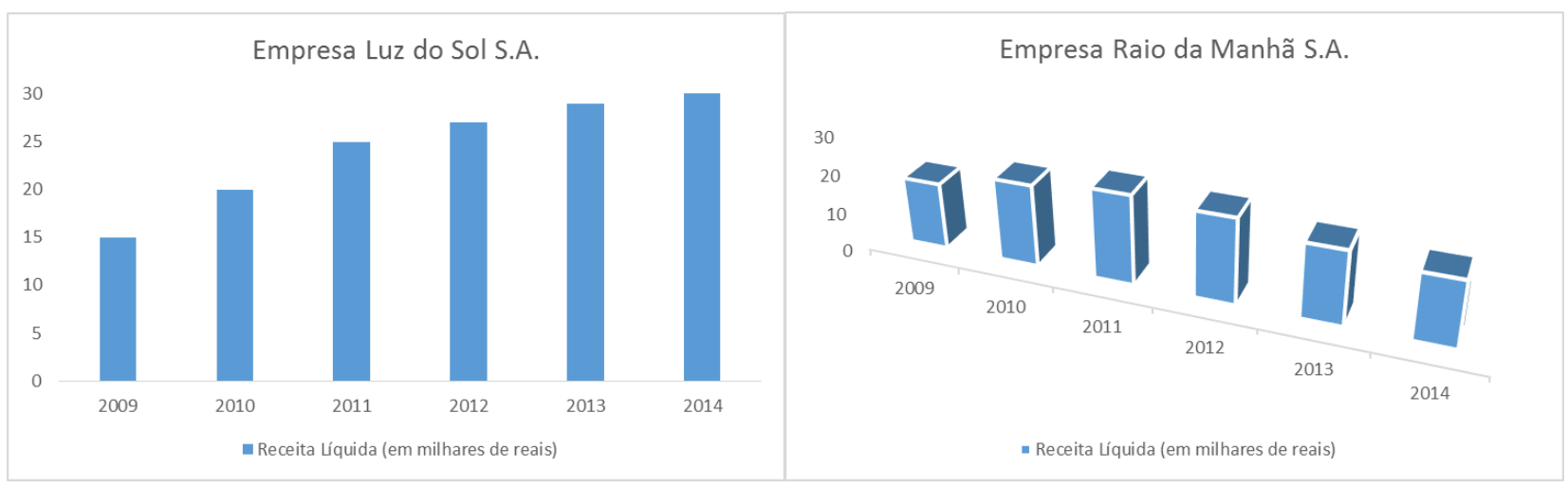

( ) Empresa Luz do Sol S.A.

( ) Empresa Raio da Manhã S.A.

( ) As duas empresas 